\author{
Teaching Assistant Ștefan Cătălin POPA, PhD Student \\ E-mail: popacatalinstefan @yahoo.com \\ Associate Professor Cezar-Petre SIMION, PhD \\ E-mail: cezarsimion@yahoo.com \\ Lecturer Simona Cătălina ȘTEFAN, PhD \\ E-mail: simona.stefan@man.ase.ro \\ Teaching Assistant Cătălina Florentina ALBU, PhD Student \\ E-mail: albucatalinaflorentina@yahoo.com \\ The Bucharest University of Economic Studies
}

\title{
STRATEGY: A BIG CHALLENGE FOR A SMALL BUSINESS. EVIDENCES FROM NORTH-EAST ROMANIAN SMES
}

\begin{abstract}
The aim of this paper is to shape an overall picture of the particularities of the exercise of the planning function within North-East Romanian SMEs.Based on the analysis of the specialized publications as well as of the preliminary researches, five hypotheses of research were formulated, one of which was fully confirmed.SMEs in the North-East Region of Romania carry out strategic planning activities, materialized by strategies. The strategic planning activities, materialized in the elaboration of policies, strategies and tactics, are not equally materialized trough documents in written form. The research carried out and presented within this article confirms a series of researches made previously including nationally for the North-West region of Romania.The results obtained have both theoretical implications by reconsidering the strategic management role for small and medium enterprises as well as managers by changing the management paradigm of SMEs from the current stage of reactive planning on short or medium terms to a future stage represented by strategic management.
\end{abstract}

Keywords: SMEs, planning, forecasting, function, strategy.

JEL Classification: C12, D22, L20, L25, M10.

\section{Introduction}

SMEs are the most important component of the Romanian economy, both in terms of their number and their contribution to GDP,playing an important role in job creation and economic growth (Aceleanu, Traşcă, \& Şerban, 2014; Van Stel, Carree \& Thurik, 2005). Most specialists believe that SMEs are both a strong pillar and a driving force of the economy, regardless of the level of the analysis (Okręglicka, Gorzeń-Mitka and Ogrean, 2015), the life of modern economies 
Ștefan Cătălin Popa, Cezar-Petre Simion, Simona Cătălina Ștefan, Cătălina Florentina Albu

(Ghobadian and Gallear, 1996) and building blocks for economic growth (Aris, 2007). They have, according to Servan-Schreiber (1967), conveyed the tacit response that the economy and society offer to the ascension of the great corporations. Increasing the complexity of the activities determines the large corporations to outsource a number of these, thus favoring the rise of SMEs.

On the other hand, SMEs can be characterized as a stage whereby large corporations move up their way to the top of economic hierarchies. From this point of view, SMEs constitute the critical mass needed for the development of large enterprises, favoring their natural selection processes. All the major corporations of our day were once in the SME category.

This type of business is characterized by a dynamic and a net adaptability that is superior to large enterprises but equally is most affected by environmental turmoil. SMEs often quickly respond to intensely competitive external environment by deploying their limited resources in a random and ad-hoc manner, rather than pursue a conscious strategic approach, thus resulting an unintended strategic approach (Grimmer, Miles, Byrom and Grimmer, 2017).

In this context, it is especially important to study the performance of the forecasting function in SMEs in different regions of Romania. The North-East Region of Romania, one of the poorest ones, greatly amplifies the problems faced by SMEs and raises a number of additional barriers to the planning function: the short-term survival pressure is much more acute due to higher incomes reduced consumption, lack of large enterprises in the value chain and market volatility.

The existence of these additional issues at regional level amplifies the motivation and the stake of research, as finding new records on the performance of the forecasting function within SMEs in the North-East Region is important from two points of view:

- From a theoretical and methodological point of view, it is important to be aware of how the managerial theories about the planning function are operationalized;

- From a pragmatic point of view, it is important to analyze the extent to which the foresight function within SMEs is exercised at regional level and what are the concrete forms of exercising this function.

The aim of this paper is to shape an overall picture of the particularities of the exercise of the planning function within North-East Romanian SMEs, throughout the research carried out, several objectives were considered, namely:

O1. To identify the strategic planning activities carried out within North-East Romanian SMEs;

O2. To analyze the influence of internal and contextual determinants on the process of development and implementation of strategy within SMEs;

O3. To identify the typology of strategies adopted by North-East Romanian SMEs, to achieve competitive advantage. 
Strategy: A Big Challenge for a Small Business. Evidences from North-East Romanian SMEs

The rest of the paper is structured as follows: The second chapter provide some insights on the concept of strategy and strategic management, along with their peculiarities within SMEs. On the basis of theoreticalapproach, previous research and own experience, five research hypotheses were formulated. The third chapter presents the research methodology, including overall research design, the selected research method and tool, sampling and data collection and data analysis procedure. In the next parts, research results are presented, followed by the concluding remarks, research implications. Future research directions are also outlined in the end of the paper.

\section{Theoretical framework}

\subsection{Strategy and strategic management}

In order to perpetuate and develop their future work in the contemporary period, all organizations, including SMEs, are compelled to implement strategies. Strategies typically include the organization's mission, strategic objectives, strategic options, the resources and implementation deadlines required (Popa, 2005). By implementing the strategies, organizations seek to achieve competitive advantage.The combination of the two types of competitive advantage (reduced cost of products/services and differentiation) with the range of firm's activities, emerge three generic strategies (Porter, 1985) that a company can use to achieve a level of performance above the industry, thus overcoming its adversaries: cost leadership, differentiation, and focus on a market niche. Without a well-defined strategy, organizations tend to behave intuitively and to react with delay and inconsistently to the external environment changes (Chladkova \& Formankova, 2016).

Strategic management is a long-term, holistic, and associated with predominantly superior management levels that determine the enterprise's vision, mission and culture (Voigt, 1992). Popa (2005) considered that strategic management is a new type of strategy-based management that aims to ensure the evolution and performance of the organization over the long term by formulating its strategy, implementing it, and continually evaluating its implementation. Strategic management allows organizations not only to react to changes in the environment but also to make these changes and contribute to environmental developments.

\subsection{The peculiarities of SMEs}

Compared to large enterprises, SMEs operate on a limited number of markets and their offer includes a much lower number of products, services or works. However, the capacity of SMEs to adapt their supply to the requirements of different markets is much higher compared to large enterprises. Kraus and Schwarz (2007) considers that the main features of SMEs are: resource, time and resource limits, focus on a single product and / or on a single market that they know very well; limits in understanding and implementing existing know-how and 
Ștefan Cătălin Popa, Cezar-Petre Simion, Simona Cătălina Ștefan, Cătălina Florentina Albu

methodologies; the strong influence that entrepreneurs have on business and their character as agents of change; faster implementation of decisions compared to large businesses.

SMEs typically have relatively low staff often strictly assigned to the operational side of their daily activities. This type of work takes almost the entire working time of the employees and sometimes of the entrepreneurs. Very often, SMEs face a lack of staff due to the absence of long-term employment contracts, preponderant use of employees and part-time work contracts, fluctuations in work, and the inability to offer their own employees the prospect of a long-term career in the same organization.

Since they do not have the financial resources of large enterprises, SMEs cannot create their own departments to deal with strategic planning, nor can they use the advice of consulting companies, at least in the start-up phase of their business. This task is most often done in an intuitive manner by the owners of such organizations. Their managers, often coming from the self-made man category, rely more on their talent in the management process and less on the formally acquired knowledge.Exercise of management functions is mainly done empirically without this category of managers taking into account the whole management process.

At the beginning of the activity of any SME, the entrepreneurs exercise the planning function, especially by planning their own business, as well as sensing the future evolution of an opportunity for its fruition. Few managers formalize their predictions in a document and are rather tempted to use their own experience than to call on specialists to make predictions.

The lack of financial resources and staff leads employers and SME managers to exercise their foresight function rather than to shape their own vision of market and business developments in the near future. The pressure to overcome SMEs makes it difficult to focus on longer terms and, implicitly, to set goals related to such deadlines.

Unlike the big business, where planning is a deliberate and sophisticated process, designed to attain a competitive level of efficiency and effectiveness, small businesses are often planning in response of particular events occurred in their operating environment. Therefore, planning in small firms is characterized by adaptive nature, short-term orientation, marked by scarce and limited available resources and highly influenced by entrepreneur personality(Yusuf and Saffu, 2005).

\subsection{Previous research on prospective dimension of SMEs management}

The research problem on the prospective dimension of SMEs management is not new, although so far has not done much research on this issue. Kraus and Schwarz (2007) analyzed how small and medium enterprises use strategic planning of their own businesses. According to the two authors, small and medium-sized 
Strategy: A Big Challenge for a Small Business. Evidences from North-East Romanian SMEs

enterprises seem to use less strategic planning than large corporations, but success seems to be a function of strategic planning use. These authors consider that strategic management is the last stage that managers and owners of SMEs can achieve in their predictive function.

Studies conducted by Berman et. al (1997), but also by other researchers (Schwenk and Shrader, 1993) showed that organizations using strategic planning achieve better financial results compared to those that do not use strategic planning. These studies were focused on the SME category, which shows the role of planning for this category of businesses. The financial results obtained are one of the most obvious forms of confirmation of the efficiency of planning processes in SMEs.

Brinckman et al. (2017) considers that business planning is a very popular management practice nowadays. These researchers have identified a number of factors that explain the individual attitudes of SME owners in planning their own businesses. They also showed that there are a number of differences in entrepreneurs' approaches to business planning.

Gica and Balint (2012) have analyzed planning practices of SMEs in North-Western Region of Romania showing that strategic planning is the best practice that SMEs can adopt if they want to increase their chances of survival and their performance. In their study, they pointed out that although most owners and managers of SMEs claim to exercise the planning function, less than $50 \%$ of them formalize this activity in strategically written plans. The strategic planning horizon is most common for up to 3 years. Almost 15\% of SME owners claimed they did not carry out predictive activities on the evolution of their own businesses.

On the other hand, according to Posner (1985), true entrepreneurs never plan. Entrepreneurs are characterized by skill, flexibility and dynamism. That's why they have a much more informal approach to planning and, in particular, to strategic management. The same idea was supported by Fuglistaller, Frey and Halter (2003) who saw in strategic management a constraint on the future development of their entrepreneurs and creativity. To a large extent, the success of a business start-up entrepreneur is due to its ability to improvise that would be affected if the entrepreneur placed himself in the strict framework of strategic management. From this point of view strategic management would be too bureaucratic for the dynamic and flexible nature of the entrepreneurs' activity. The same authors consider that time is an important resource for the owners of SMEs, and it is more devoted to research - development, sales or other operational activities, and less to strategic planning.

So far, no research focused on the exercise of the forecasting function in SMEs in the North-East region of Romania has been carried out. Such a study is all the more useful because it can be compared with the data obtained by Gica and Balint (2012) for the North-West region of Romania. 
Ștefan Cătălin Popa, Cezar-Petre Simion, Simona Cătălina Ștefan, Cătălina Florentina Albu

\subsection{Research hypotheses}

The research hypotheses were formulated on the basis of the previous results revealed by other studies published in the literature but also on the basis of previous own research which provided a number of additional indications for their confirmation.

H1: Most SMEs in the North-East Romania carry out strategic planning activities, resulting in policies, strategies and tactics.

The formulation of this hypothesis is based on the results of studies conducted by Brinckman et al. (2017) and those by Gica and Balint (2012) for the North-West region of Romania. Kraus and Schwarz(2007)also showed that strategic planning is the final stage of the foreseeable approach to small and medium-sized businesses.

Moreover, a survey carried out at national level (Nicolescu et al., 2017) revealed that in 2017 more than half of the SMEs managers in Romania (56.89\%) showed interest in the prospective dimension of the management, materialized in the development of strategies (19.13\%) and annual plans and policies (37.76\%). Therefore, the first aspect to be considered in the research was to determine the extent to which SMEs in the North-East region carry out strategic planning activities. Previous research carried out at national level indicated that the prospective dimension of the Romanian SMEs management, materialized in the development of annual policies and plans and strategies for 3-5 years, is insufficiently capitalized.

H2: The strategic planning activities, materialized in the elaboration of policies, strategies and tactics, are not equally materialized trough documents in written form.

The second hypothesis of the research is also based on the results obtained by Gica and Balint (2012) for the North-West region of Romania. Managers and owners of SMEs have a more informal approach to the planning process without wanting or having time to convey their own vision in written documents.

H3: The development of policies, strategies and tactics varies according to the field of activity, age and size of SMEs.

Several previous studies have shown that the results of the strategic planning process vary according to several factors including the size of SMEs and their age. The field of activity is mentioned as a factor that can affect the development of policies and strategies in relatively few of the previous studies.

H4: The internal environment factors exert a greater influence on the process of elaboration and implementation of SMEs' strategy compared to external (contextual) determinants. 
Strategy: A Big Challenge for a Small Business. Evidences from North-East Romanian SMEs

The fourth hypothesis was formulated without a benchmark in earlier studies published in specialized literature for the SME field. For other organizations, previous research shows the preference of internal factors as compared to external factors in formulating and implementing strategies at the organization level.

H5: In order to achieve competitive advantage, the North-Est Romanian SMEs are focusing mainly on differentiation strategies.

There are no previous studies confirming this hypothesis in Romanian context, however, however due to lack of resources and experience, startups are expected to pursue a differentiation strategy for a niche market, while SMEs that have a long-term survival rate and/or achieve superior performance have adopted differentiation strategies or combined differentiation with cost-efficiency (Leitner and Güldenberg, 2010). Thus, in a study carried out by Leitner and Güldenberg (2010) on 100 Austrian SMEs on 1995 and 2003 was found that, from the generic strategies, the analyzed firms pursued mainly a pure differentiation strategy, followed by those who combined quality differentiation and product innovation with cost-efficiency strategies, while a pure cost leadership type was followed only by a minority of firms. The study did not consider the focus strategy.Given that integration into the EU and labor market liberalization put pressure on labor costs, it is expected that in the future Romanian SMEs will target the competitive advantage based on differentiation.

\section{Methodology}

\subsection{Overall research design}

In order to accomplish the purpose of the research, to achieve the established objectives (both theoretically and empirically), a general research design was conceived, with several phases:

1. The first phase involved mainly bibliographic documentation, by consulting a wide range of specialized literature). Also, during the documentation phase, experts in strategic management and managers of SMEs performing strategic planning activities were consulted. The information thus obtained has allowed us to outline a first picture of the particularities of strategy use and strategic management in SMEs in Romania, generally identifying some of their particular aspects in the North-East region, as well as formulating research hypotheses.

2. The second phase consisted of an empirical research, which highlighted the main features of the strategic planning activities carried out within North-East Romanian SMEs. The main research method used at this stage was the survey, and the research instrument - the questionnaire. The data obtained on this occasion also allowed the validation of the assumptions of the research. 
Ștefan Cătălin Popa, Cezar-Petre Simion, Simona Cătălina Ștefan, Cătălina Florentina Albu

\subsection{Research method and tool}

Whereas, to achieve the research objectives, it was necessary to collect a large amount of structured data from a specialized population (small and mediumsized enterprises), spread over a relatively broad geographic area (the North-East region of Romania), the survey was chosen as a research method, and the structured questionnaire as research tool. Both face-to-face and the online questionnaire (for businesses that were harder to address in terms of geographic location) were used, each of them presenting specific advantages but also disadvantages and limits.

In the process of designing the questionnaire, the purpose and objectives of the research were primarily considered, both the type and content of the questions being chosen in such a way that the resulting variables to allow the validation of the research hypotheses. The questionnaire was structured in two parts. (1) The first part consisted of 10 questions and was dedicated to collecting the demographics of the respondents as well as identifying the relevant features of the investigated firms. (2) The second part covered 21 questions related to various aspects of SMEs strategic planning process, of which, to achieve the objectives of the present paper, only data resulted from five of them was considered.

\subsection{Research population and sampling}

The surveyed population was represented by small and medium-sized enterprises, as defined by the "User guide to the SME Definition" (European Commission, 2015), having its headquarters in a strictly defined geographic area, namely the North East Region Romania, respectively counties: Bacau, Botoșani, Iasi, Neamt, Suceava and Vaslui. According to the National Institute of Statistics (2018), in 2016 there were 57,764 active SMEs in the North-East region, of which 50,857 micro-enterprises (between 0 and 9 employees), 5,882 small enterprises (between 10 and 49 employees) and 1,025 medium-sized businesses (between 50 and 249 employees). Although it would have been desirable for the sampling method to be a probabilistic one, the lack of a sampling frame, including a complete list of SMEs in the North-East region, as well as their contact details, determined as to choose the "snowball" sampling.

\subsection{Procedure}

Around 500 questionnaires were distributed both by electronic mail and at the headquarters of companies. Of these, 245 were actually completed (online or physically), the response rate being $49.00 \%$. Unfortunately, 39 questionnaires could not be used due to the large amount of missing data. Consequently, the final sample, based on the responses to which all subsequent analyzes were made, was 206 respondents.

The actual data analysis involved descriptive statistics elements (percentage, mean, standard deviation), while the research hypotheses were validated by applying specific statistical tests (Chi-Square Test, McNamar Test, 
Strategy: A Big Challenge for a Small Business. Evidences from North-East Romanian SMEs

Paired Samples T-Test, Cochran's Q test and Dunn's pairwise test), using IBM SPSS Statistics software package, version 25.0.

\section{Results and discussions}

\subsection{Preliminary data analysis}

Preliminary data processing involved verification of completeness of dataset by means of missing data analysis. Unfortunately, 39 of the 245 questionnaires had a large percentage of missing data, which required not to be considered for further analysis. For the rest of dataset, expectation maximization (EM) algorithm was employed for data imputation.

The characteristics of the 206 companies considered relevant are shown in Table 1. As far as the field of activity is concerned, among the 206 selected SMEs to be part of the sample, more than one third (41.26\%) are active in the field services, $27.67 \%$ in the industry, $20.39 \%$ in the trade, $9.22 \%$ are transport companies and only $1.46 \%$ are active in the construction sector. Considering the age of the companies participating in the survey, their distribution is balanced, meaning that most of them (26.21\%) were set up 10 to 15 years ago, $25.73 \%$ - 5 to $10,17.48 \%$ are over 20 years old, while $15.06 \%$ are younger than 5 years and $15.53 \%$ are aged between 15 and 20 years old. Regarding the number of employees, almost half of the SMEs (42.23\%) fall into the category of micro enterprises, about one third (33.50\%) are small enterprises, and $24.27 \%$ are medium enterprises.

Table 1. Characteristics of SMEs in the sample

\begin{tabular}{|c|c|c|c|c|c|}
\hline \multicolumn{2}{|c|}{ Characteristics } & Frequency & Percent & $\begin{array}{c}\text { Valid } \\
\text { Percent }\end{array}$ & $\begin{array}{c}\text { Cumulative } \\
\text { Percent }\end{array}$ \\
\hline \multirow{6}{*}{$\begin{array}{l}\text { Field of } \\
\text { activity }\end{array}$} & Trade & 42 & $20.39 \%$ & $20.39 \%$ & $20.39 \%$ \\
\hline & Construction & 3 & $1.46 \%$ & $1.46 \%$ & $21.84 \%$ \\
\hline & Industry & 57 & $27.67 \%$ & $27.67 \%$ & $49.51 \%$ \\
\hline & Services & 85 & $41.26 \%$ & $41.26 \%$ & $90.78 \%$ \\
\hline & Transport & 19 & $9.22 \%$ & $9.22 \%$ & $100.00 \%$ \\
\hline & Total & 206 & $100.00 \%$ & $100.00 \%$ & \\
\hline \multirow{6}{*}{$\begin{array}{c}\text { The } \\
\text { company's } \\
\text { age }\end{array}$} & Under 5 years & 31 & $15.05 \%$ & $15.05 \%$ & $15.05 \%$ \\
\hline & Between 5 and 10 years & 53 & $25.73 \%$ & $25.73 \%$ & $40.78 \%$ \\
\hline & Between 10 and 15 years & 54 & $26.21 \%$ & $26.21 \%$ & $66.99 \%$ \\
\hline & Between 15 and 20 years & 32 & $15.53 \%$ & $15.53 \%$ & $82.52 \%$ \\
\hline & Over 20 years & 36 & $17.48 \%$ & $17.48 \%$ & $100.00 \%$ \\
\hline & Total & 206 & $100.00 \%$ & $100.00 \%$ & \\
\hline \multirow{4}{*}{$\begin{array}{l}\text { Company } \\
\text { size }\end{array}$} & Microenterprise & 87 & $42.23 \%$ & $42.23 \%$ & $42.23 \%$ \\
\hline & Small enterprise & 69 & $33.50 \%$ & $33.50 \%$ & $75.73 \%$ \\
\hline & Medium enterprise & 50 & $24.27 \%$ & $24.27 \%$ & $100.00 \%$ \\
\hline & Total & 206 & $100.00 \%$ & $100.00 \%$ & \\
\hline
\end{tabular}

Source: Own representation based on survey data

\subsection{Strategic planning activities carried out by SMEs}

The analysis of data obtained from the application of the questionnaire, revealed that $93.20 \%$ of the respondents stated that within their organization are 
Ștefan Cătălin Popa, Cezar-Petre Simion, Simona Cătălina Ștefan, Cătălina Florentina Albu

developed strategic planning activities. Of these, strategies are developed in the largest proportion of SMEs (64.56\%), followed by policies $(41.75 \%)$ and tactics $(34.95 \%)$.

Comparing these data with the above, one can see that, in terms of developing policies and tactics, results are comparable. Thus, in the previous research, the percentage of SMEs developing annual plans and policies for the period 2009-2017 range between $35.67 \%$ in 2015 and 53.33\% in 2009, while in the North-East 2017 survey, 34.95\% of SMEs are developing tactics and $41.75 \%$ policies. The results are somewhat different, but all the more encouraging, in terms of strategy development, as national multiannual percentages varied between $5.96 \%$ and $13.85 \%$, while in the current survey $64.55 \%$ of the respondents said that they are engaged in strategic planning activities materialized in strategies. These differences may be partly justified by the differences between the two surveys in terms of geographical coverage, time frame and applied methodology.

Analyzing the data presented above may justify us partially accepting hypothesis no. 1, meaning that most SMEs in the North-East region of Romania carry out strategical planning activities that have been materialized in the development of strategies, but for further accuracy and to extrapolate the results to the population surveyed, we will resort to test it. In this respect, Chi-square goodness to fit tests were calculated comparing the observed percentage with a hypothesized occurrence of $50 \%$. As one can see in table 2, significant differences were found, as follows: (1) less than 50\% of SMEs in the North-East Romania carry out strategic planning activities, materialized through policy $\left(\chi_{(1)}^{2}=5.612\right.$, $p<0.05)$ and tactics $\left(\chi_{(1)}^{2}=18.660, p<0.01\right)$, while $(2)$ more than $50 \%$ of SMEs carry out strategic planning activities, materialized through strategy development $\left(\chi^{2}(1)=17.476, p<0.01\right)$. Thus, hypothesis no. 1 can only be partially validated in the sense that most SMEs in the North-East Romania carry out strategic planning activities, materialized by strategies.The validation of the first hypothesis taken into account confirms, in part, some previous results presented in the studies published by Brinckman et al (2017) and those by Gica and Balint (2012).

Table 2. Strategic planning activities carried out by SMEs - Chi-Square Test

\begin{tabular}{clcccc}
\hline No. & Strategic activities & Observed \% & Expected \% & $\chi^{\mathbf{2}}$ & p \\
\hline 1 & Policies & $41.75 \%$ & $50.00 \%$ & 5.612 & 0.018 \\
2 & Strategies & $64.56 \%$ & $50.00 \%$ & 17.476 & 0.000 \\
3 & Tactics & $34.95 \%$ & $50.00 \%$ & 18.660 & 0.000 \\
\hline
\end{tabular}

Source: Own representation based on survey data

Another aspect of SMEs policies, strategies and tactics development that has been addressed in the research was the extent to which they have also a written form, as specific document. Table 3 shows that there are differences between the percentages in which each of the strategic documents is drawn up and the percentages in which they have a written form. Thus, the smallest difference can be 
Strategy: A Big Challenge for a Small Business. Evidences from North-East Romanian SMEs

found for policies (7.77 p.p.), followed by strategies (13.59 p.p.), while tactics are the least transposed in written form within SMEs, the difference being 14.56 p.p.

In order to validate hypothesis 2 and determine if the differences in the proportion of SMEs developing policies, strategies and tactics and the extent to which they have also a written form are statistically significant, exact McNemar's test was employed. As can be seen in Table 3, the percentage differences are statistically significant $(p<0.01)$, so that hypothesis 2 can be validated and we can say that the strategic planning activities, materialized in the elaboration of policies, strategies and tactics, are not equally materialized trough documents in written form.

Table 3. Strategic planning activities carried out by SMEs - McNamar Test

\begin{tabular}{ccccccc}
\hline No. & $\begin{array}{c}\text { Strategic } \\
\text { activities }\end{array}$ & $\begin{array}{c}\text { Are } \\
\text { realized }\end{array}$ & $\begin{array}{c}\text { Are realized in } \\
\text { written form }\end{array}$ & Difference & $\chi^{2}$ & $\boldsymbol{p}$ \\
\hline 1 & Policies & $41.75 \%$ & $33.98 \%$ & $7.77 \%$ & - & $0.000^{*}$ \\
2 & Strategies & $64.56 \%$ & $50.97 \%$ & $13.59 \%$ & 26.036 & 0.000 \\
3 & Tactics & $34.95 \%$ & $20.39 \%$ & $14.56 \%$ & 26.281 & 0.000 \\
\hline
\end{tabular}

Note:* Binominal distribution used. Source: Own representation based on survey data

Validation of the second hypothesis of research confirms the findings of Gica and Balint's (2012) research for SMEs in the Northwest of Romania. Much of the Romanian SMEs tend not to formalize the results of strategic planning processes in writing. Significantly, studies conducted in two different regions achieved approximately the same results over a six-year period.

It is also relevant to the distribution of responses according to the three characteristics of SMEs, namely: the field of activity, their age and their size. Thus, taking into account the first of these characteristics, the field of activity, one can notice (table 4): (1) nearly half of SMEs active in industry (49.12\%) and services $(43.53 \%)$ are developing policies, while none of the construction firms are doing so, (2) tactics are most commonly addressed by transport companies $(57.89 \%)$, and (3) those in the services and transport sector have the largest percentage of the SMEs that develop strategies.

Table 4. Strategic planning activities carried out by SMEs - Chi-Square Test

\begin{tabular}{|c|c|c|c|c|c|c|c|}
\hline \multirow{2}{*}{ No. } & \multirow{2}{*}{ Elements } & \multicolumn{4}{|c|}{ Field of activity } & \multirow{2}{*}{$\chi^{2}$} & \multirow[b]{2}{*}{$p$} \\
\hline & & Trade & Industry & Services & Transport & & \\
\hline 1 & Policies & $35.71 \%$ & $49.12 \%$ & $43.53 \%$ & $31.58 \%$ & 2.779 & 0.427 \\
\hline 2 & Strategies & $50.00 \%$ & $61.40 \%$ & $72.94 \%$ & $68.42 \%$ & 6.871 & 0.076 \\
\hline 3 & Tactics & $19.05 \%$ & $31.58 \%$ & $40.00 \%$ & $57.89 \%$ & 10.306 & 0.016 \\
\hline
\end{tabular}

Source: Own representation based on survey data

As a result of the grouping of SMEs according to their age, a number of particular aspects can be observed, which refer to (see table 5): (1) the intensity with which SMEs perform strategic planning activities increases with their age, this positive correlation being particularly noticeable for policies and strategies, the percentage of entrepreneurs who have declared that they are developing increases 
Ștefan Cătălin Popa, Cezar-Petre Simion, Simona Cătălina Ștefan, Cătălina Florentina Albu

with the age of SMEs, from $22.58 \%$ to $66.67 \%$, respectively from $51.61 \%$ to $83.33 \%$, (2) with respect to development of tactics, there seems to be no general trend, but only a minimum of $20.75 \%$ noticeable for firms within 5 to 10 years old and a maximum $(52.78 \%)$ for those older than 20 years.

Table 5.Strategic planning activities carried out by SMEs- Chi-Square Test

\begin{tabular}{|c|c|c|c|c|c|c|c|c|}
\hline \multirow[b]{2}{*}{ No. } & \multirow[b]{2}{*}{ Elements } & \multicolumn{5}{|c|}{ Company's age } & \multirow[b]{2}{*}{$\chi^{2}$} & \multirow[b]{2}{*}{$p$} \\
\hline & & $\begin{array}{c}\text { Under } 5 \\
\text { years }\end{array}$ & $\begin{array}{c}5-10 \\
\text { years }\end{array}$ & $\begin{array}{l}\text { 10-15 } \\
\text { years }\end{array}$ & $\begin{array}{l}15-20 \\
\text { years }\end{array}$ & $\begin{array}{c}\text { Over } 20 \\
\text { years }\end{array}$ & & \\
\hline 1 & Policies & $22.58 \%$ & $39.62 \%$ & $25.93 \%$ & $62.50 \%$ & $66.67 \%$ & 25.199 & 0.000 \\
\hline 2 & Strategies & $51.61 \%$ & $60.38 \%$ & $64.81 \%$ & $62.50 \%$ & $83.33 \%$ & 8.283 & 0.082 \\
\hline 3 & Tactics & $35.48 \%$ & $20.75 \%$ & $42.59 \%$ & $25.00 \%$ & $52.78 \%$ & 12.515 & 0.014 \\
\hline
\end{tabular}

Source: Own representation based on survey data

The analysis of responses grouped by size of SMEs (table 6) mainly highlights the following: (1) There is a positive correlation between the size of firms and the extent to which they generally carry out strategic planning activities. (2) In case of strategies and tactics, this relationship is much more obvious given that the percentage that entrepreneurs have declared that they are producing these documents increases from $48.28 \%$, respectively $25.29 \%$ for micro-enterprises to $82.00 \%$ and $50.00 \%$ respectively for medium-sized enterprises. (3) In terms of policy development, there is no significant difference between micro $(35.63 \%)$ and small companies $(33.33 \%)$, but stands a rate nearly doubled $(64.00 \%)$ for medium enterprises.

Table 6.Strategic planning activities carried out by SMEs- Chi-Square Test

\begin{tabular}{ccccccc}
\hline \multirow{2}{*}{ No. } & \multirow{2}{*}{ Elements } & \multicolumn{3}{c}{ Company size } & \multirow{2}{*}{$\chi^{2}$} & $p$ \\
\cline { 3 - 5 } & & Microenterprise & Small nterprise & Medium enterprise & & \\
\hline 1 & Policies & $35.63 \%$ & $33.33 \%$ & $64.00 \%$ & 13.527 & 0.001 \\
2 & Strategies & $48.28 \%$ & $72.46 \%$ & $82.00 \%$ & 18.614 & 0.000 \\
3 & Tactics & $25.29 \%$ & $36.23 \%$ & $50.00 \%$ & 8.604 & 0.014 \\
\hline
\end{tabular}

Source: Own representation based on survey data

From the data presented above, we may conclude that the development of policies, strategies and tactics differ according to the field of activity, age and size of SMEs. In order to validate hypothesis no. 3, taking into account the type of variables analyzed, to highlight the association between the strategic planning activities of SMEs and their different characteristics (field of activity, age and size) we employed the $\chi^{2}$ test.The results obtained are presented in Tables 4,5 and 6 , the last two columns.

From the data presented above, one can conclude that: (1) As far as policies are concerned, the $\chi^{2}$ test revealed that the extent to which they are developed in SMEs differs according to the age $\left(\chi_{(4)}^{2}=25.199, p=.000\right)$ and size of the firms $\left(\chi_{(2)}^{2}=13.527, p=0.001\right)$, while the field of activity has no influence $\left(\chi^{2}(3)=2.779, \mathrm{~ns}\right)$. (2) The size of the firm is associated with the extent to which 
Strategy: A Big Challenge for a Small Business. Evidences from North-East Romanian SMEs

they develop strategies $\left(\chi_{(2)}^{2}=18.614, p=0.000\right)$, while, at the level of the general population, there is no statistically significant association between the elaboration of strategies and the field of activity $\left(\chi_{(3)}^{2}=6.871, \mathrm{~ns}\right)$ and the age $\left(\chi^{2}(4)=8.283\right.$, ns $)$ of SMEs. (3) The percentage of SMEs that develop tactics varies according to the field of activity $\left(\chi_{(3)}^{2}=10.316, p=0.016\right)$, the age $\left(\chi_{(4)}^{2}=12.515, p=0.014\right)$ and size $\left(\chi_{(2)}^{2}=8.604, p=0.014\right)$.In conclusion, hypothesis no. 3 is partially validated.

\subsection{Determinants of strategy}

Considering the determinants of strategy, among the many existing theoretical approaches, in this research it was adopted the one that divides them, depending on the area they come from, in internal and external (contextual) determinants (Popa, 2005).

With respect to the internal determinants (Table 7), in the opinion of the respondents, the greatest influence on the development and implementation of strategy in SMEs have the owners $(M=4.12, s d=1.069)$ and top management $(M$ $=4.06, s d=1.056)$, ie those who are directly interested and involved in this process. Other important determinants of the SME strategy are those corresponding to the different categories of strategic resources, namely: the economic status of the organization $(M=3.57, s d=0.976)$, human potential $(M=3.54, s d=0.952)$, technical endowment and technologies $(M=3.48, s d=1.025)$ and information and knowledge potential $(M=3.37, s d=0.880)$. A lower, but significant, influence is exerted by factors that may be associated with the organizational structure, such as: company size $(M=3.26, s d=1.067)$, complexity of the organization $(\mathrm{M}=3.01$, sd $=0.878)$ and territorial dispersion of subdivisions $(M=2.59, s d=0.917)$. These results are explicable by the specificity of SMEs in terms of these characteristics. Unfortunately, the organizational culture $(M=2.93, s d=0.640)$ was found on the penultimate place among the determinants of the strategy, denoting the insufficient emphasis it received within SMEs.

As one can see in Table 7, contextual determinants, overall, exert a lower influence on SMEs strategy than internal ones. Among them,stand out the economic factors $(M=3.85, s d=0.983)$, managerial $(M=3.64, s d=1.006)$ and technical and technological $(M=3.43, s d=1.067)$. At the opposite side, the lowest influence corresponds to socio-cultural factors $(M=2.70, s d=0.709)$ and the ecological ones $(M=2.62, s d=0.915)$.

Table 7. Determinants of strategy - Descriptive Statistics

\begin{tabular}{llcccc}
\hline \multicolumn{1}{c}{ No. } & \multicolumn{1}{c}{ Factors } & N & Mean & $\begin{array}{c}\text { Std. } \\
\text { Deviation }\end{array}$ & Variance \\
\hline Internal determinants & $\mathbf{2 0 6}$ & $\mathbf{3 . 3 9}$ & $\mathbf{0 . 5 2 3}$ & $\mathbf{0 . 2 7 4}$ \\
\hline 1 & Top management & 206 & 4.06 & 1.056 & 1.116 \\
2 & Company size & 206 & 3.26 & 1.067 & 1.138 \\
3 & Complexity of the organization & 206 & 3.01 & 0.878 & 0.771 \\
4 & Technical endowment and technologies & 206 & 3.48 & 1.025 & 1.050 \\
5 & Territorial dispersion of subdivisions & 206 & 2.59 & 0.917 & 0.841 \\
6 & Human potential & 206 & 3.54 & 0.952 & 0.906 \\
\hline
\end{tabular}


Ștefan Cătălin Popa, Cezar-Petre Simion, Simona Cătălina Ștefan, Cătălina Florentina Albu

\begin{tabular}{llllll}
\hline 7 & Organization culture & 206 & 2.93 & 0.640 & 0.409 \\
8 & The economic status of the organization & 206 & 3.57 & 0.976 & 0.952 \\
9 & Information and knowledge potential & 206 & 3.37 & 0.880 & 0.774 \\
10 & The owner & 206 & 4.12 & 1.069 & 1.143 \\
\hline External (contextual) determinants & $\mathbf{2 0 6}$ & $\mathbf{3 . 1 9}$ & $\mathbf{0 . 5 9 8}$ & $\mathbf{0 . 3 5 8}$ \\
\hline 1 & Economic & 206 & 3.85 & 0.983 & 0.967 \\
2 & Managerial & 206 & 3.64 & 1.006 & 1.012 \\
3 & Technical and technological & 206 & 3.43 & 1.067 & 1.139 \\
4 & Ecological & 206 & 2.62 & 0.915 & 0.837 \\
5 & Legal & 206 & 3.18 & 0.926 & 0.857 \\
6 & Political & 206 & 2.91 & 0.763 & 0.582 \\
7 & Socio-cultural & 206 & 2.70 & 0.709 & 0.503 \\
\hline
\end{tabular}

Source: Own representation based on survey data

In order to validate hypothesis 4 , two aggregate variables were first defined, calculated as the average of the two sets of values corresponding to the level of influence of the ten internal factors and the seven contextual factors. In order to determine whether there are statistically significant differences between the averages of these two variables, thus validating hypothesis 4, the PairedSamples T-Test was employed. The results showed that there are significant differences $\left(\mathrm{t}_{(205)}=6.001, p<0.001\right)$ between the mean of variable corresponding to the influence of internal factors on the process of developing and implementing the SMEs strategy $(M=3.391, s d=0.524)$ and that of the variable corresponding to its contextual (external) determinants $(M=3.189, s d=0.598)$, thus supporting the fourth hypothesis.

\subsection{Types of strategies adopted by SMEs}

In investigating the types of strategies adopted by North East Romanian SMEs, it was considered the classification according to Porter's generic strategies, emerged by combining the two types of competitive advantages (reduced cost of products/services and differentiation) with the range of firm's activities (Porter, 1985): cost leadership, differentiation, and focus on a market niche.

The results of the survey revealed that most SMEs (72.82\%) have adopted a product / service differentiation strategy or cost-oriented strategy (62.62\%), while a nearly two-fold lower share of companies $(32,04 \%)$ sought to obtain competitive advantage by finding a market niche. Five of the respondents $(2.43 \%)$ said their own company had adopted a different strategy than the ones mentioned above (see table 8).

Table 8.Types of strategies adopted by SMEs - Descriptive Statistics

\begin{tabular}{clcc}
\hline No. & \multicolumn{1}{c}{ Porter's generic strategies } & Frequency & Percent \\
\hline 1 & Cost leadership & 129 & $62.62 \%$ \\
2 & Product / service differentiation & 150 & $72.82 \%$ \\
3 & Focus strategy & 66 & $32.04 \%$ \\
4 & Others & 5 & $2.43 \%$ \\
\hline & Total & $\mathbf{3 5 0}$ & $\mathbf{1 6 9 . 9 1 \%}$ \\
\hline
\end{tabular}

Source:Own representation based on survey data 
Strategy: A Big Challenge for a Small Business. Evidences from North-East Romanian SMEs

In order validate the fifth hypothesis, first we determined whether there are statistically significant differences in the proportion of SMEs adopted the three Porters generic strategies. Thus, a Cochran's Q test determined that there was a statistically significant difference in the proportion of SMEs adopted cost-oriented strategy, product / service differentiation strategy and focused on finding a niche market $\left(\chi_{(2)}^{2}=67.447, p<0.001\right)$. In the second step, Dunn's pairwise tests adjusted with Bonferroni correction were carried out for the three pairs ofstrategies. There was very strong evidence $(p<0.001)$ of differences between the percentages of SMEs focused on a niche market and those adopting cost leadership and product/service strategies.However, there was no evidence of difference between the latter $p=0.145$ ). Thus, there are no statistical evidences to support the fifth hypothesis.

It should also be noted that most of the SMEs investigated said they did not exclusively focus on one type of strategy, rather adopting one or another of the possible combinations, thus confirming the results regarding this matter of the study carried out by Leitner and Güldenberg (2010) in Austrian environment.

However, there was not expected that percentage of SMEs pursuing a cost leadership strategy to be so high. On this matter the results are somehow similar with those of Parnell, Long and Lester (2015), who found that Chinese SMEs tend to prefer cost-based approaches to their local markets in contrast with the USA, where differentiated products and services stand a substantially greater chance of success. They explain those differences trough the different levels of disposable income, witch lead to more or less market opportunities for SMEs.

\section{Conclusions}

The realization of the research within this article aimed at highlighting the peculiarities and determinants of the foresight function for the SMEs in the NorthEast region of Romania with a focus on strategic planning. Based on the results and conclusions of other studies previously published in the literature, as well as previous own preliminary researches, five hypotheses of the research presented in this article were formulated. The analysis of the obtained results allowed the confirmation of the second hypothesis of the research.

According to this hypothesis, strategic planning activities, materialized in the elaboration of policies, strategies and tactics, are not materially materialized through written documents. Also, the analysis of the results allowed partial confirmation of the first hypothesis as well as of the third hypothesis of the research. SMEs in the region carry out strategic planning activities, materialized by strategies.

The full validation of the second hypothesis, as well as the partial hypothesis of the first hypothesis, confirms a series of results obtained by other authors in previous studies either internationally or for SMEs in other regions of Romania. From this 
Ștefan Cătălin Popa, Cezar-Petre Simion, Simona Cătălina Ștefan, Cătălina Florentina Albu

point of view, the study has as the main theoretical implication that the exercise of the foresight function in the Romanian SMEs implies a number of peculiarities among which the most obvious are: the desire of the managers of the SMEs to exercise the foresight function but the lack of the preoccupation for the formalization the results of the written forecast.

The research has a number of obvious managerial implications: the need to change the management paradigm of SMEs from the current stage of reactive planning and short or medium term to a future stage represented by strategic management; awareness of SME managers about the relationship between the exercise of the forecasting function and the performance achieved.

The main limit of research stems from the non-probability sampling method adopted, thus not allowing the results obtained to be generalized. Other limitations are those associated with the two approaches of the research method: (1) the "face to face" survey, involving a high consumption of time and resources, thus limiting the number of respondents, and (2) the online survey, associated with a low response rate low and also a low responsibility in completing the questionnaires.

In the future researches on this topic, we will seek to expand the field of research of the particularities of the exercise of the forecasting function and of the SMEs from other development regions of Romania, in a comparative approach with those made in this article. Another direction of further research in this article is the analysis of the differences between different types of SMEs in the exercise of the foresight function and, in particular, of the strategic planning.

\section{REFERENCES}

[1] Aceleanu, M.I., Traşcă, D.L. \& Şerban, A.C. (2014),The Role of Small and Medium Enterprises in Improving Employment and in the Post-crisis Resumption of Economic Growth in Romania.Theoretical and Applied Economics, XXI(1 (590)), 87-102;

[2] Aris, N.M. (2007),SMEs: Building Blocks for Economic Growth.National Statistics Conference, Department of National Statistics, Malaysia;

[3] Berman, J.A, Gordon, D.D., Sussman, G. (1997), A Study to Determine the Benefits Small Business Firms Derive from Sophisticated Planning versus Less Sophisticated Types of Planning; Journal of Business and Economic Studies, 3(3),1-11;

[4] Brinckmann, J., Dew, N., Read, S, Mayer-Haug, K., Grichnik, D. (2017),Of those who Plan: A Meta-analysis of the Relationship between Human Capital and Business Planning; Long Range Planning xxx (2017), 1-16, DOI:10.1016/j.lrp.2018.01.003; 
Strategy: A Big Challenge for a Small Business. Evidences from North-East Romanian SMEs

[5] Chladkova, H. \& Formankova, S. (2016), Strategy for SMEs in the Area of Primary Agricultural Production. Agricultural Economics, 62(9), 395406, DOI:10.17221/260/2015-AGRICECON;

[6] European Commission. (2015), User guide to the SME Definition. Retrieved May 10, 2018, from European Commission: https://ec.europa.eu/ growth/content/revised-user-guide-sme-definition-0_en.

[7] Fuglistaller, U., Frey, U., Halter, F. (2003), Strategisches management fur KMU- eine praxisorienterte Anleitung, KMU HSG, St. Gallen;

[8] Ghobadian, A., Gallear, D.N. (1996), Total Quality Management in SMEs. Omega 24(1), 83-106, DOI:10.1016/0305-0483(95)00055-0.

[9] Gică, O.A, Balint, I.C., (2012), Planning Practices of SMEs in NorthWestern Region of Romania. An empirical investigation,Procedia Economics and Finance, 3, 896-901, DOI:10.1016/S2212-5671(12)00247$\mathrm{X}$.

[10] Grimmer, L., Miles, M.P., Byrom, J. and Grimmer, M. (2017),The Impact of Resources and Strategic Orientation on Small Retail Firm Performance. Journal of Small Business Management, 55(51), 7-26. DOI:10.1111/jsbm.12368;

[11] Leitner, K., \& Güldenberg, S. (2010), Generic Strategies and Firm Performance in SMEs: A Longitudinal Study of Austrian SMEs. Small Business Economics, 35(2), 169-189,DOI:10.1007/s11187-009-9239-x;

[12] Kraus, S., Schwarz, E.J. (2007), The Role of Pre-start-up Planning in New Small Business, International Journal of Management and Enterprise Development, 4(1), 1-17, DOI:10.1504/IJMED.2007.011452;

[13] National Institute of Statistics. (2018), Statistica Întreprinderilor. Retrieved April 20, 2018, from TEMPO Online: http://statistici.insse.ro/ shop/index.jsp?page $=$ tempo2\&lang $=$ ro\&context $=55$;

[14] Nicolescu, O., Nicolescu, C., Urîtu, D., Corcodel, S,.F., Ștefan, S.C. \& Truică, A.P. (2017), Carta Albă a IMM-urilor din România în 2017. București: ProUniversitaria;

[15] Okręglicka, M., Gorzeń-Mitka, I., Ogrean, C. (2015), Management Challenges in the Context of a Complex View - SMEs Perspective, Procedia Economics and Finance, 34, 445-452, DOI:10.1016/S22125671(15)01653-6;

[16] Parnell, J.A., Long, Z., Lester, D. (2015), Competitive Strategy, Capabilities and Uncertainty in Small and Medium Sized Enterprises (SMEs) in China and the United States, Management Decision, 53(2), 402431, DOI:10.1108/MD-04-2014-0222;

[17] Popa I. (2005), Management general, Bucharest; ASE Publishing;

[18] Porter, M.E. (1985), Competitive Advantage. Creating and Sustaining Superior Performance. First Free Press Edition; 
Ștefan Cătălin Popa, Cezar-Petre Simion, Simona Cătălina Ștefan, Cătălina Florentina Albu

[19] Posner, B.G, (1985),Real Entrepreneurs don't Plan.Inc., 7(11), 129-132;

[20] Schwenk, C.R, Shrader, C.B. (1993), Effects of Formal Strategic Planning on Financial Performance in Small Firms - A Meta Analysis.Entrepreneurship: Theory and Practice, 17(3), 53-64;

[21] Servan-Schreiber, J. J. (1967), Le défi américain. Denoel, Paris;

[22] Van Stel, A., Carree, M. \& Thurik, R. (2005), The Effect of Entrepreneurial Activity on National Economic Growth. Small business economics, 24(3), 311-321, DOI:10.1007/s11187-005-1996-6;

[23] Voigt, K.I. (1992), StrategischePlanung und Unsicherheit, Springer;

[24] Yusuf, A. and Saffu, K. (2005), Planning and Performance of Small and Medium Enterprise Operators in a Country in Transition.Journal of Small Business Management, 43, 480-497,DOI:10.1111/j.1540627X.2005.00148.x. 